\title{
EL KRAUSISMO Y LA OBRA TEMPRANA DE RAMÓN PÉREZ DE AYALA: LA TETRALOGÍA DE DÍAZ DE GUZMÁN
}

\author{
Daniel Rueda Garrido \\ Universidad Normal de Hebei
}

\section{RESUMEN}

La obra novelística de Ramón Pérez de Ayala en su primera época $(1907$ - 1913) está construida según la ley de progreso histórico del ideal krausista. Ese ideal supone la integración de las partes en el todo, es decir, la asimilación sucesiva de los conjuntos humanos por el individuo en un proceso gradual de comprensión de sus características esenciales. El medio idóneo para esa comprensión universal es la educación estética, que favorece la imaginación por la concordancia de la razón y los sentidos. El momento cumbre de ese progreso es un estado definido como armonía con todo lo existente, y esto se aprecia tanto en la filosofía krausista de la historia como en la biografía de Díaz de Guzmán.

PALABRAS CLAVE: Ramón Pérez de Ayala, progreso histórico, educación estética, ideal krausista, tetralogía

\section{ABSTRACT}

The early novels of Ramón Pérez de Ayala (1907 - 1913) are designed to follow the law of historical progress related to the Krausist ideal. That ideal is understood as the integration of the parts, that is to say, the gradual assimilation and comprehension of the essential characteristics of the human groups.

Recibido: 19-03-2014 / Aceptado: 02-04-2014 


\section{Daniel Rueda Garrido}

To comprehend this takes an aesthetic education, which reinforce and help develop the imagination through the collaboration of reason and senses. The top of this human progress is a state of harmony with every existing thing, and that can be seen in the Krausist Philosophy of History as well as in the biography of Díaz de Guzmán.

KEY WORDS: Ramón Pérez de Ayala, historical progress, aesthetic education, Krausist ideal, tetralogy

\section{ESTADO DE LA CUESTIÓN}

El primer autor que prestó alguna atención sobre este aspecto de la obra del escritor asturiano, concretamente sobre el panteísmo de su poesía en relación con el krausismo, fue Víctor García de la Concha en su Tesis doctoral titulada Los senderos poéticos de Ramón Pérez de Ayala, en la colección Archivum de la Universidad de Oviedo en 1970. Tras él, otros estudiosos de la obra de Pérez de Ayala han mencionado a vuela pluma la influencia que la ILE tuvo en la formación del futuro escritor, como hace Andrés Amorós en la introducción a su edición de Troteras y danzaderas, y en algunos casos han funcionado de acicate para nuevos investigadores llamando la atención sobre el interés que podría significar un acercamiento a la obra del autor desde las enseñanzas krausistas, como sugiere Gamallo Fierros en un artículo para el volumen de homenaje a Ramón Pérez de Ayala en el centenario de su nacimiento (1980). En los últimos años ha sido la profesora Ángeles Prado, fundamentalmente en el estudio introductorio a su edición de Tigre Juan. El curandero de su honra (2001), quien ha resaltado la importancia de este aspecto en la obra del autor que nos ocupa, sobre todo en las novelas que han venido a llamarse normativas, las de la última época, en que la ideología krausista queda plenamente asimilada en la exposición de unas normas universales y valores vitales dependientes de la armonía cósmica preestablecida.

El primer estudio de conjunto sobre la influencia del krausismo en Ramón Pérez de Ayala fue realizado en 1998 por Prieto Jambrina en su Tesis doctoral: El humanismo armónico de Ramón Pérez de Ayala. Este estudio fundamenta esta filiación krausista del escritor astur, principalmente, en dos evidencias: la primera, un artículo del propio Pérez de Ayala publicado en la revista Helios en 1903 y titulado: «Liras o lanzas». El artículo respondía al libro de Álvaro de Albornoz, «No liras, lanzas», y en él el escritor astur defiende un punto intermedio en el debate sobre el arte por el arte o el arte como compromiso social. Llegado el momento culminante del artículo, Pérez de Ayala se afirma en su filiación krausista de este modo:

Pero cátate que Albornoz y yo somos krausistas hace tiempo, hemos bebido en las mismas fuentes de conocimiento, nos educamos en una misma disciplina científica. 
¡Bendito rayo de luz! Ningún libro mejor que El ideal de la humanidad, de Krause, para inquirir cuál sea mi deber. ${ }^{1}$

Este párrafo ha merecido el comentario - digo el comentario porque hasta este estudio de Prieto Jambrina no se había profundizado en el sentido que pudiera arrojar sobre la obra total de Pérez de Ayala - de diferentes críticos como García de la Concha o Gamallo Fierros.

La segunda evidencia es el prólogo a la edición argentina de Troteras y danzaderas, publicado en Buenos Aires por la editorial Losada en 1942. En ese prólogo, Prieto Jambrina encuentra las claves de interpretación de toda la obra del escritor asturiano. En él, el mismo Pérez de Ayala traza las aristas que formaron su proyecto literario además de aportar notas importantes sobre su ideología, y su estética en particular. Como el mismo Jambrina explica en su trabajo, la legitimidad de dicho prólogo como clave interpretativa ha sido puesta en duda por críticos como Andrés Amorós, para quien la exégesis que hace Ayala de su propia obra en aquella época no era más que un modo de darle unidad y, por tanto, de reconstruirla bajo un esquema intencionado lejos de la pretensión originaria de aquellos textos. ${ }^{2}$ Jambrina, sin embargo, justifica su elección argumentando que si no de un modo acabado y consciente, sí habría informado la obra novelística del autor aquellas a modo de intuiciones y como borradores de lo que sería su plan literario final. ${ }^{3}$ Para Jambrina dicho plan está basado en una idea general de impronta krausista y que consistía, como Ayala dice en el prólogo, en el análisis de la evolución de la conciencia desde el individuo a su disolución en la conciencia universal.

Al proyecto narrativo de sus cuatro primeras novelas, Pérez de Ayala denomina con unas frases tomadas de Beethoven y Goethe, respectivamente: «por el dolor a la alegría» y «de la sombra a la claridad». Esa tetralogía formaba parte de un plan más vasto que quedó inconcluso, según el escritor asturiano, y que precisamente plasmaría ese proceso de desvelamiento de las normas eternas y la verdad, mediante el análisis doloroso de la realidad a través de la conciencia de su protagonista. Este plan dirá Pérez

\footnotetext{
1 «[...] en medio de la polémica del momento entre el concepto de un arte socialmente comprometido y el arte por el arte, se muestra partidario de un término medio, donde el arte, abierto a una visión universal de la humanidad, ha de ser entendido como el único horizonte en el que se puede mantener la tensión que suscita el planteamiento, irresoluto por cualquier otro medio, de los grandes interrogantes que fundamentan todo interés por la vida tanto de uno mismo como de los demás, idea indudablemente krausista», en: Prieto Jambrina, El humanismo armónico de Ramón Pérez de Ayala, Alicante, Universidad de Alicante, 1998, p. 7.

2 A. Amorós, Vida y literatura en «Troteras y danzaderas», Madrid, Castalia, 1973, p. 17.

3 «Estoy completamente convencido, y es lo que me propongo mostrar a lo largo del presente trabajo, de que Ayala desarrolla toda su obra narrativa bajo el resplandor de la idea esencial de la versión española del krausismo», en: Prieto Jambrina, El humanismo armónico de Ramón Pérez de Ayala, Alicante, Universidad de Alicante, 1998, p. 7.
} 
de Ayala fue remendado mediante la creación del modelo mixto que son las novelas poemáticas, camino de fusión de ambas vías de intelección de la verdad, y cerrar el ciclo novelesco con «la recreación en presente de algunas de las normas eternas y los valores vitales», ${ }^{4}$ pudiendo calificar, como sugiere en el mismo prólogo, a toda su producción novelesca con el adagio de «a la poesía por la verdad». ${ }^{5}$

Como valores vitales, Ayala menciona en el prólogo los siguientes: religión, ética y estética, que no son más que ideas platónicas insertas en el nivel antropológico, las cuales corresponderían en el plano ontológico a: Verdad, Bien y Belleza. La persecución de esos tres valores vitales recorrerá el proyecto novelístico de Ayala teniendo como norte las normas eternas de las que estos valores dimanan. ${ }^{6}$ Según Jambrina, el proyecto literario trazaría un proceso que comienza con la introspección del yo, (Tinieblas en las cumbres), el resultado de esa introspección es la necesidad de salir de uno mismo y encontrarse con los demás como modo de salvación y realización personal (La pata de la raposa). La realización personal consiste en la hombredad, la razón de ser del hombre en el plan universal es comportarse como hombre, y este consta de espíritu y naturaleza. La afirmación del espíritu solo viene mediante la afirmación de la propia personalidad (A.M.D.G), y la expresión de esa personalidad se realiza mediante la búsqueda de la verdad (valor vital). Para Ayala el sistema más apropiado para llegar a la verdad es la sensibilidad estética (Troteras y danzaderas), la cual, en la belleza (valor vital), encuentra la unión armoniosa de espíritu racional y sentidos naturales. La ética - que gira en torno al bien - (valor vital), la búsqueda del bien propio y común, a modo de prolongación del yo en los otros, viene dada por la fuerza de la naturaleza - la otra parte constitutiva del hombre - en dos formas: la búsqueda de la mujer compañera, como medio de realizar la realidad integral en el amor erótico (Luna de miel, luna de hiel, y Los trabajos de Urbano y Simona); y la búsqueda de la perpetuación en el amor genesíaco (Tigre Juan y el curandero de su honra).

El sentido de la trayectoria de su novelística dentro de ese proyecto ideológico literario general la resume Jambrina del siguiente modo:

La razón de ser del individuo debe completarse más allá de las fronteras de su propio yo; ha de sentirse dentro de una proyección universal cuya concreción tendrá lugar en la humanidad en cuanto manifestación finita del Espíritu Absoluto, Dios. $^{7}$

\footnotetext{
4 Pérez de Ayala, «Prólogo» en Troteras y danzaderas, Buenos Aires, Losada, 1942, p. 19.

5 Pérez de Ayala, «Prólogo» en Troteras y danzaderas, Buenos Aires, Losada, 1942, p. 18.

${ }^{6}$ «Esas normas eternas no son ni pueden entenderse como creaciones del hombre, sino que, por el contrario, ellas son, como diría Goethe, las madres, quienes actuando por caminos inescrutables, al final llegarán a manifestarse como tales», en: Pérez de Ayala, «Prólogo» en Troteras y danzaderas, Buenos Aires, Losada, 1942, p. 36.

7 Prieto Jambrina, El humanismo armónico de Ramón Pérez de Ayala, Alicante, Universidad de Alicante, 
Partiendo de la Tesis de Prieto Jambrina, expongo en estas páginas un estudio interpretativo del krausismo de Ayala circunscrito a la tetralogía de su alter ego, Alberto Díaz de Guzmán. Comparto las dudas que presentó Andrés Amorós acerca de que toda la obra del autor asturiano estuviese escrita según la idea global defendida en el prólogo de 1942; pero considero que en su tetralogía - tomada como una obra unitaria (1902 - 1913) y cuando tenía más reciente las enseñanzas krausistas e institucionistas -, se puede apreciar un desarrollo desde la individualidad indiferenciada a la toma de conciencia de la universalidad de la experiencia humana. Ese proceso se cumple en tres etapas - unidad, pluralidad, armonía -, y en él se plasma la ley de la historia descrita en el Ideal de la humanidad para la vida de Sanz del Río. Para que esta concepción krausista de la historia y del progreso integral de la humanidad quede explicada desde el interior de la obra ayalina, considero fundamental, primero, un acercamiento a la significación profunda que el ideal tiene tanto en la forma como en el contenido de la obra de Ramón Pérez de Ayala; y, en segundo lugar, un análisis de la función que el autor otorga a la educación estética para la formación y realización de ese ideal, el cual requiere la asimilación de lo humano en sus diversos niveles, tanto el histórico y cultural como el social y geográfico.

\section{CONCEPCIÓN DE LA HISTORIA EN LA TETRALOGÍA AYALINA: EL HOMBRE UNIVERSAL}

El final del proceso en que se sitúa al protagonista de la tetralogía ayalina viene representado por la última parte de La pata de la raposa, cuando Alberto Díaz de Guzmán ha dejado Madrid, ciudad en la que había tomado conciencia de su nación y de su carácter español tras tres años de vida literaria - reflejada en Troteras y danzaderas -. En este momento cumbre, se encuentra en una ciudad italiana, Lugano, ${ }^{8}$ dispuesto a volver a su patria chica, su provincia. El personaje a estas alturas de la narración ha tomado conciencia de sí mismo y ha asimilado su posición en el universo, descubriendo valores esenciales de la moral y la estética, así como la comprensión de que todo era digno de ser amado; se describen entonces unos momentos de plena armonía con todo

1998, p. 13.

8 Que sea fuera de España (Italia) donde aparece ambientada esta última parte del proceso de formación de Díaz de Guzmán, no deja de tener relevancia, pues el conocimiento de la nación propia requería tanto un primer momento de ensimismamiento como un segundo de enajenación, es decir, de mirarla desde dentro y desde fuera para llegar a un estado de ecuanimidad y armonía entre ambos, movimiento intelectual que tiene que ver con la teoría del conocimiento krausista y la objetivación del sujeto por la que se persigue la universalización del sentimiento humano, muy en relación con la catarsis dramática tal y como es descrita en Troteras: «Todo consiste en meterse entre los bastidores de uno mismo, introspeccionarse, convertirse de actor en espectador y mirar del revés la liviandad y burda estofa de todos esos bastidores, bambalinas y tramoya del sentimiento humano», en: Pérez de Ayala, Obras completas, Vol. I, García Mercadal (ed.), Madrid, Aguilar, 1963, p. 690. 
lo existente mediante un sentimiento de simpatía universal: «Había llegado a proyectar una simpatía universal sobre todo lo creado, a amar a todo por igual». ${ }^{9}$

En la novela a la que me vengo refiriendo, la imagen de la raposa como representación simbólica de una actitud esencialmente vitalista en lucha contra el pesimismoSchopenhaueriano, forma partedeun proceso más amplio quees labúsqueda de ideales para la vida por parte de Alberto. Este proceso concluye provisionalmente en la última parte de La pata de la raposa con el estado de autoconciencia y armonía que alcanza el protagonista, quien había llegado «al soberano bien, al equilibrio, al imperio de sí propio, a la unidad»:

Por último se recogía dentro de sí propio, con los párpados cerrados, a gozarse en los deleites intelectuales y estéticos de sentir destilada en su espíritu la realidad, y no la realidad hermética e inerte de la materia, sino una realidad templada, traslúcida y expresiva. Recreación. ${ }^{10}$

Este último momento de la tetralogía de Díaz de Guzmán es el culmen de un proceso dialéctico de perfeccionamiento en deuda con el Ideal de la humanidad, puesto que, como he dicho arriba y según este la humanidad había de recorrer tres edades para alcanzar su plenitud: indiferenciación, pluralidad y armonía. ${ }^{11}$ Trayectoria que equivaldría respectivamente al siguiente orden en las novelas de la tetralogía: $A M D G$ y Tinieblas en las cumbres (indiferenciación, o, usando una terminología ayalina de la obra de madurez y que Jambrina analiza: ensimismamiento); La pata de la raposa entrarían solamente las dos primeras partes, «La noche», $\mathrm{y}$ «El alba»-, junto a Troteras y danzaderas, (representan la pluralidad o enajenación); y por último, la parte final de La pata de la raposa, esto es, la titulada «La tarde» (armonía). ${ }^{12}$

Este esquema conceptual, que se corona con el estado de plenitud y armonía humanas, supone dos experiencias previas en el protagonista: la toma de conciencia del carácter provincial asturiano (concentrado elocuentemente en AMDG, Tinieblas en las cumbres y La pata de la raposa) y la comprensión del carácter nacional (expresado en Troteras y danzaderas). Por todo lo cual se puede entender que Alberto representa como

\footnotetext{
9 Pérez de Ayala, Obras completas, Vol. I., García Mercadal (ed.), Madrid, Aguilar, 1963, p. 445.

10 Pérez de Ayala, Obras completas, Vol. I., García Mercadal (ed.), Madrid, Aguilar, 1963, p. 445.

11 «La ley histórica: que en todo ser y vida limitada se produce en primer grado una variedad de manifestaciones aisladas en particularidad y oposición; que luego la unidad recibe en sí aquellas manifestaciones primeras simples, y que últimamente en la edad plena la unidad reuniéndose con su interior variedad se convierte en una armonía viva y orgánica», en: K. Ch. F. Krause /J. Sanz del Río, Ideal de la humanidad para la vida, Barcelona, Ediciones Folio, 2002, p. 192.

12 Esta estructuración de la tetralogía se ha hecho siguiendo la concepción de novela única y lineal en cuatro partes que ha establecido $\mathrm{M}^{\mathrm{a}}$ del Carmen Bobes Naves. Ver «Renovación del relato en las primeras novelas de D. Ramón Pérez de Ayala», en: Pérez de Ayala visto en su centenario. 1880-1980, Oviedo, IDEA, 1980, pp. 73-97.
} 
en epítome el devenir del individuo en su humanidad esencial, puesto que el ideal de esa humanidad:

[...] pide al individuo, respecto a las sociedades humanas, los hombres mayores, en las que él se contiene con toda su historia, que reconociéndose parte y órgano de estos individuos mayores, la familia, el pueblo, la nación, la humanidad, viva con ellos en continua y progresiva relación para el cumplimiento del fin fundamental del todo y el histórico de cada sociedad humana. ${ }^{13}$

\section{EL IDEAL ${ }^{14}$}

La importancia de ese ideal en el pensamiento y cosmovisión del escritor astur rebasa el contenido para dejarse entrever también en la forma. No obstante, desde el krausismo, la armonía entre los diferentes componentes es esencial a la obra artística. ${ }^{15}$ En esta sección pretendo señalar cómo dicha armonía se da en su obra novelística. Que hay unidad y pluralidad se entiende por el cúmulo de episodios, personajes, oposiciones de perspectivas y cambios de opiniones que constituyen la tetralogía de Alberto Díaz de Guzmán. Todos estos elementos entran en unidad desde la concepción krausista del desenvolvimiento de la humanidad en tres edades: unidad indiferenciada, pluralidad y armonía. ${ }^{16}$ Esta última para ser perfecta debe abarcar todos los aspectos de la obra, así dice Pérez de Ayala de las cualidades esenciales de lo poemático: «La perfección poemática reside en el equilibrio entre el fondo y la superficie, entre la materia y la forma; presión y represión». ${ }^{17} \mathrm{Y}$ así también, Azorín, comentando la obra de Ayala, asegura: «[...] la forma - vocabulario y sintaxis - está siempre de acuerdo en estos libros con la sutilidad y originalidad del pensamiento. Y eso es el arte: armonía suprema de todos los componentes de la obra». ${ }^{18}$

13 K. Ch. F. Krause / J. Sanz del Río, Ideal de la humanidad para la vida, Barcelona, Folio, 2002, pp. 48-9.

14 Actualmente, en mi Tesis doctoral, estoy llevando a cabo un estudio detallado sobre la noción de Ideal en relación con la teoría de la acción, y de la importancia de ambas para la actividad general del krausismo español y, en concreto, de su pedagogía.

15 En: J. Krause, «La unidad con la pluralidad y variedad de lo bello constituyen su armonía, tercera categoría, en que la variedad, enlazada a la unidad como tal, forma un todo compuesto o de unión, propio y sustantivo en el concierto de sus partes». K. Ch. F. Krause, Compendio de estética, trad. y anotada por F. Giner de los Ríos, Madrid, librería de V. Suárez, 1883, p. 28.

16 Como apunta Capellán de Miguel en su estudio general del krausismo español, ese momento cumbre del progreso de la humanidad, es la materialización del ideal: «[...] lo más interesante de la Filosofía de la Historia krausiana son dos elementos principales. En primer lugar, hay que destacar que se trata de un proceso claramente teleológico: toda la Historia de la Humanidad se encamina a un punto último cuya realidad es encarnada por el Ideal. Ese Ideal no es otro que la Alianza global de la Humanidad en la tierra, compuesta de todas las uniones parciales que ya ha expuesto previamente y que debían producirse en cada una de las esferas particulares de la vida al cumplir el hombre con el fin propio de cada una de ellas». G. Capellán de Miguel, La España armónica, Madrid, Biblioteca Nueva, 2006, p. 77.

17 Pérez de Ayala, Obras completas, Vol. I, Madrid, Aguilar, 1963, p. 229.

18 Pérez de Ayala, Obras completas, Vol. I, Madrid, Aguilar, 1963, p. 58. 
De acuerdo con esto, el Ideal de la humanidad para la vida que rige su más profunda elaboración espiritual, se complementa con la forma de la creación artística y su textura literaria. La forma biográfica es la idónea para la representación del progreso de la humanidad, pues el mismo Pérez de Ayala escribió de forma diáfana que «la historia de un individuo es la síntesis y compendio de la historia de toda la humanidad». ${ }^{19}$ De ahí el que la vida de Alberto Díaz de Guzmán sea siempre algo más que una simple vida individual; con él se analiza un proceso más vasto de asimilación de la propia esencia y reflexión sobre el género humano en su devenir hacia la edad plena y armónica. En este proceso hallamos el ideal como medio de percepción de la realidad; la idealización a la que están sometidos los personajes y en general todos los seres y acontecimientos de la tetralogía refieren una intención artística. ${ }^{20}$ Si tenemos en cuenta la definición que del ideal nos brinda el autor en uno de sus artículos de «Terranova y sus cosas» de 1911, se puede apreciar un poco mejor lo que entiende por «ideal»:

El ideal está en la perfección dentro de la naturaleza de cada ser. El ideal de un huevo consiste en otro huevo más ovalado que todos los demás y el de una fregona en otra fregona que tipifique la esencia y excelencia de todas las fregonas. Por donde vea usted que el ideal no es sino extracto y concentración de lo real. ${ }^{21}$

Quedémonos con esta definición, que me parece la más idónea para comprender el modo idealizador de la literatura ayalina.

Según estos dos movimientos del ideal, el resultado es una universalización de los caracteres que han sido extraídos de la realidad mediante su concentración en una unidad ideal. De este modo, presento más abajo algunos de los diferentes mecanismos que Pérez de Ayala utiliza para universalizar o generalizar los elementos de su universo literario, teniendo en cuenta que lo concreto siempre apunta a su universalización o generalización en la experiencia humana, y que mediante el relato de hechos particulares, está narrando el progreso de la humanidad. Este recurso idealizador aparece sobre todo en las dos novelas intermedias del ciclo, esto es, Tinieblas en las cumbres y La pata de la raposa, pues el inicio temporal de la tetralogía, AMDG, donde se cuenta la vida de Bertuco en el colegio de jesuitas, está anclado en la concreción local, en la que aún no se presiente la comunión con el destino humano, sino que predomina la falta de diferenciación entre la experiencia propia y la del resto de la humanidad, siendo el periodo de la formación de la personalidad del protagonista;

\footnotetext{
19 Pérez de Ayala, Tributo a Inglaterra, Madrid, Aguilar, 1963, p. 107.

20 De gran importancia considero la aportación que hizo Donald Shaw al respecto de la idealidad de la literatura de Pérez de Ayala: «Harking back to the vaguely Krausist concept of la idealidad de lo real, launched by his old teacher, Ayala was to postulate a few months later the awareness vouchsafed to poets of idealidad materializado as something fundamental to the process of creation». «Modernismo, idealism and the intellectual crisis in Spain, 1895 - 1910», en: Renaissance and Modern Studies, Vol. XXV, Nottingham, University of Nottingham, 1981, p. 35.

${ }^{21}$ Pérez de Ayala, Obras completas, Madrid, Aguilar, 1963, p. 1295. Las cursivas son mías.
} 
y en Troteras y danzaderas, por ser el momento de concienciación del carácter patrio, abundan, sobre todo, las generalizaciones sobre los rasgos esenciales de los españoles, en los que reverberan ecos de la humanidad. Esta idealización no solo opera sobre las características humanas sino sobre todos los objetos del entorno, describiendo la realidad desde una perspectiva sub especie aeternitatis. Los ejemplos que presento a continuación no pretenden sino ser una muestra de lo que vengo diciendo hasta el momento sobre la textura ideal de la literatura de Pérez de Ayala en relación siempre indisoluble con el contenido y las convicciones filosóficas del autor.

Son muchos los ejemplos que se encuentran en la tetralogía de la técnica por la cual se establecen personas o sucesos como epítomes de su tipo, o en otras palabras, como prototipos o ideales. Uno de los más usados es el recurso retórico de la antonomasia. De este modo, se extiende a sus personajes los rasgos característicos de personas y obras de la historia y la cultura en general, confundidos todos en una misma unidad esencial por la cual lo propiamente humano elimina barreras de tiempo y lugar, como cuando se refiere a las fiestas de los amigos de Alberto: «Si bien él las reputaba por placenteras y brillantes en mayor grado que las de Sardanápalo». ${ }^{22} \mathrm{O}$ a la identificación de Rosina con la reina de Saba: «Pasa Rosina [...] introdúcete, reina de Saba, en los retiros del rey». ${ }^{23} \mathrm{Y}$ la comparación culta con pinturas que representan un estilo definido, y por las cuales la idealidad de la narración ayalina toma una perspectiva de segundo grado, es decir, se ve el arte - el pasaje de su obra - a través de otra obra de arte - el conocido cuadro de Rubens -: «Sugería el recuerdo de esas hembras pingües y fáciles que en las Kermeses de Rubens [...]». ${ }^{24}$

Otro recurso es el de la comparación clásica entre edades de la historia, lo cual refuerza el carácter humano de los hechos de sus personajes, como en el símil del paso del Rubicón y la hazaña moral del personaje que sortea tentaciones de los arrabales de la ciudad: «A unos cuantos pasos del Rubicón moral que corre misteriosamente, vedando lenocinios arrabales». ${ }^{25}$

Esta técnica suele ir también acompañada de la ironía por la cual se incide en la distancia temporal, con lo que consigue el efecto contrario al que hasta ahora he mostrado, es decir, no acerca el objeto a su prototipo, sino que señala la diferencia o recorrido hasta llegar a él. En cierta forma, con esta técnica también se deja entrever la intención de colorar el texto de un cierto clasicismo o de elevar al estatus clásico su literatura: «Así como en la antigüedad clásica el falo de bronce sobre el dintel era de

\footnotetext{
22 Pérez de Ayala, Obras completas, Vol. I, Madrid, Aguilar, 1963, p. 11.

23 Pérez de Ayala, Obras completas, Vol. I, Madrid, Aguilar, 1963, p. 227.

24 Pérez de Ayala, Obras completas, Vol. I, Madrid, Aguilar, 1963, p. 259.

25 Pérez de Ayala, Obras completas, Vol. I, Madrid, Aguilar, 1963, p. 18.
} 
equívoca elocuencia, en esta edad prosaica las verdes persianas corridas hacen el oficio de signos rituales». ${ }^{26} \mathrm{E}$ igualmente en:

Divinos atenienses: vosotros, en la cumbre luminosa de la Acrópolis, al pie de la áurea Palas Atenea de Fidias, consagrasteis una leona simbólica, a la cual faltaba la lengua, en recuerdo del mutismo de esta hetaira [...] Nosotros, si queremos consagrar alguna estatua emblemática a nuestras cortesanas. ${ }^{27}$

Otro recurso retórico utilizado abundantemente en la tetralogía es el de la definitio, con el cual se define un objeto de modo que se le presenta superior o inferior a lo que le corresponde, en ambos casos estamos ante una idealización de la realidad, o bien para marcar la dirección desde la que verla en su excelencia e idealidad - a veces teñida de reflexión filosófica -, o bien, por oposición, para denunciar el trayecto que la separa de ella: «No era la hembra salvaje, brusca e insolente, de lengua avisada y manos recias, sino la criatura sencilla, un poco de égloga a fuerza de timidez». ${ }^{28} \mathrm{Y}$ la reflexión sobre aspectos relacionados con la condición humana, que elevan a intelectualidad el hecho narrado: «La fascinación del juego está en que bajo una acción se desvanece el sentido del tiempo». ${ }^{29}$

En cuanto a la intertextualidad en la obra de Pérez de Ayala, tiene esta la misma función idealizadora, puesto que con ella se hace acopio de voces ajenas que al aparecer reunidas en el texto refuerzan, no obstante, la unidad de sentido de la cultura humana; y esto lo consigue mediante la referencia a autores clásicos, como en este ejemplo en que se refiere al sueño: « [...] estado estúpido que Homero llamó hermano de la muerte». ${ }^{30}$ Pero también dejando resonar ecos de esos autores, sin citarlos, como en esta referencia indirecta a San Juan de la Cruz: «Ríanse los suspiros largos de Rosina que, el rostro reclinado sobre el amado, dejábase». ${ }^{31} \mathrm{Y}$ con la cita textual de clásicos antiguos: «¿No recuerda usted las palabras del rey hermoso, sabio y concupiscente? Pues oiga: No hay bien para el hombre sino que coma y beba». ${ }^{32} \mathrm{Y}$ de modernos: - «Se hizo presente en su memoria los versos de Mallarmé: La chair est triste, helas! Et j'ai lu tous les livres». ${ }^{33}$

26 Pérez de Ayala, Obras completas, Vol. I, Madrid, Aguilar, 1963, p. 14.

27 Pérez de Ayala, Obras completas, Vol. I, Madrid, Aguilar, 1963, p. 109.

28 Pérez de Ayala, Obras completas, Vol. I, Madrid, Aguilar, 1963, p. 26.

29 Pérez de Ayala, Obras completas, Vol. I, Madrid, Aguilar, 1963, p. 668.

30 Pérez de Ayala, Obras completas, Vol. I, Madrid, Aguilar, 1963, p. 72.

31 Pérez de Ayala, Obras completas, Vol. I, Madrid, Aguilar, 1963, p. 73.

32 Pérez de Ayala, Obras completas, Vol. I, Madrid, Aguilar, 1963, p. 216.

33 Pérez de Ayala, Obras completas, Vol. I, Madrid, Aguilar, 1963, p. 258. 
El humorismo o ironía cómica es otro modo negativo de marcar la distancia con el ideal. Respondiendo a la definición que el mismo autor nos da del humorismo: «discernir y sentir la sublimidad invertida de un mundo tonto», ${ }^{34}$ se entiende que Pérez de Ayala muestra en sus personajes esas propensiones humanas a considerar sublime - especialmente, su propia persona - lo que no es sino insignificante. Y teniendo en cuenta que para Pérez de Ayala el ridículo es «la conciencia de la desproporción entre el propósito y el acto», ${ }^{35}$ el humorismo se puede entender como el desvelar compasivo del ridículo humano. Ejemplo de ello es el enfrentamiento entre opiniones distintas - la del autor y la del personaje - que presuponen, no obstante, el perspectivismo: «Parecían ojos de rana o de ratón de cría. Él, sin embargo, teníalos por la obra más acabada del cosmos». ${ }^{36}$ En el ejemplo de abajo la personificación ridícula del edificio podría significar lo destartalado y desproporcionado de sus elementos: «El edificio parecía recibirle asombrado de verle volver, con los ojos de los balcones enarcados, y la boca del balcón como alelada. Los rosales del tapial temblaron de emoción». ${ }^{37}$ Este dotar de vida lo inerte es también característico de Pérez de Ayala, y asimismo indica la decisión de espiritualizar o idealizar toda la realidad insistiendo en el destino común de todo lo existente, actitud que se relaciona también con el krausismo en tanto que este predica el conocimiento fundamental de lo universal y permanente:

Debemos lo primero volver al conocimiento más profundo de nuestra naturaleza en su realidad permanente, en su universal igualdad entre todos los hombres, y en su relación armónica con todos los seres. ${ }^{38}$

El recurso contrario al de la idealización positiva es el de la animalización, también muy usado por el escritor astur, y que, como el de la ironía, supone el ideal desde su negativo. De manera que estando los hombres destinados a la perfección de su plena humanidad, estos personajes animalizados muestran un grado anterior y como una mayor lejanía de aquel ideal humano; representan la humanidad de esos personajes del modo en que un negativo contiene la imagen revelada. Algunos ejemplos de ello son: «Cerdá era una especie de sátiro, producido en las boscosidades de la provincia de Lérida», ${ }^{39} \mathrm{y}$ « [...] no era una vaca, pero tenía algo de simpática animalidad, de ave inofensiva y temerosa», refiriéndose a Rosina. ${ }^{40}$

\footnotetext{
34 Pérez de Ayala, Obras completas, Vol. I, Madrid, Aguilar, 1963, p. 337.

35 Pérez de Ayala, Obras completas, Vol. I, Madrid, Aguilar, 1963, p. 431.

36 Pérez de Ayala, Obras completas, Vol. I, Madrid, Aguilar, 1963, p. 27.

37 Pérez de Ayala, Obras completas, Vol. I, Madrid, Aguilar, 1963, p. 402.

38 K. Ch. F. Krause / J. Sanz del Río, Ideal de la humanidad para la vida, Barcelona, Folio, 2002, p.42.

39 Pérez de Ayala, Obras completas, Vol. I, Madrid, Aguilar, 1963, p. 5.

40 Pérez de Ayala, Obras completas, Vol. I, Madrid, Aguilar, 1963, p. 23.
} 
La idealización de la experiencia humana o recurso alegórico es un método con el que el autor desvela notas de la condición humana, insistiendo así en lo universal de las acciones de sus personajes y en la identificación del lector con ellas. Así, sirva de ejemplo estas líneas de Tinieblas en las cumbres: «Sus frases, sobre poco más o menos, eran las mismas que había pronunciado mucho antes que ellos miles y miles de individuos». ${ }^{41}$

Es en Troteras y danzaderas donde se concentran los intentos de definir y generalizar el carácter español, ya que tomando conciencia de él y sintiéndose parte de él, como sucede a Alberto Díaz de Guzmán, que es apenas parte del ambiente social, se anda más cerca de la toma de conciencia de la humanidad esencial de cada uno, para lo cual la integración en los grupos humanos supeditados es, según la doctrina krausista, una exigencia del ideal:

Asimismo, cada individuo y cada sociedad humana sólo entonces realizan la plenitud de su idea, cuando ligándose de grado en grado en relación comprensiva y supremamente con la sociedad total humana, abracen con igual interés y en acción común y orgánica todos sus fines; cuando ordenen toda condición y relación humana en forma de un armonismo interior, vivo y total. ${ }^{42}$

La condición indispensable para llegar a la plenitud de la humanidad y como paso previo a la nación es, por tanto, la conciencia de la región, que en Pérez de Ayala se percibe sobre todo en los poemas de La paz del sendero (1904), aunque tanto Tinieblas como La pata estén ambientadas y como caladas de ese ambiente regional asturiano, en Pilares o Cenciella, denotando con esas descripciones locales el conocimiento preciso de aquellos grupos humanos.

En cuanto al carácter español, su toma de conciencia implica una invectiva desde la condición humana esencial relativa al ideal krausista. Con respecto a la educación española que crea parte de ese carácter, alza una amarga queja: «A los veinticinco años somos viejos y la menor contrariedad nos aniquila. Somos hombres sin niñez y sin juventud, espectros de hombres». ${ }^{43} Y$ sobre la tradicional falta de voluntad del pueblo español, apunta: «España ha sido un pueblo de quimeras: nunca ha sabido lo que ha querido». ${ }^{44} Y$ esta falta de voluntad, de espíritu y, en definitiva, de «hombredad» - con el vocablo que inventó Pérez de Ayala - es con lo que el español tiene que lidiar si quiere colaborar al progreso de la humanidad tal y como lo dicta el ideal del que ya hemos hecho algunas anotaciones.

\footnotetext{
41 Pérez de Ayala, Obras completas, Vol. I, Madrid, Aguilar, 1963, p. 70.

42 K. Ch. F. Krause / J. Sanz del Río, Ideal de la humanidad para la vida, Barcelona, Folio, 2002, pp. 88-89.

43 Pérez de Ayala, Obras completas, Vol. I, Madrid, Aguilar, 1963, p. 694.

44 Pérez de Ayala, Obras completas, Vol. I, Madrid, Aguilar, 1963, p. 705.
} 
La armonía entre fondo y forma, como quería Pérez de Ayala, se percibe en los ejemplos aducidos, pues hay un constante prurito de universalizar la experiencia, reconocer un baldío común para el espíritu humano; sin embargo, esta armonía no sería total sin la contrapartida - la de la pluralidad - de discursos concretos y específicos; sin las particularidades que muestran las historias narradas; y sin la diferenciación expedita en caracteres individuales y provinciales. Prueba de ello son los numerosos diálogos en que el personaje catalán emplea su lengua, o el bable asturiano de Rosina y su familia, o las particularidades de los sectores marginados de la sociedad como es el de las prostitutas (Tinieblas en las cumbres) y los presos (La pata de la raposa).

Para comprender el alcance de lo dicho sobre el específico valor del ideal en la obra de Pérez de Ayala hay que desglosar las ideas que Giner de los Ríos expresó sobre la capacidad de la literatura para plasmar el carácter de una nación. ${ }^{45}$ Conocer la vida de un pueblo en plenitud significa conocer algo más que sus instituciones, su vida política, sus hazañas militares, sus costumbres y tradiciones; de estos hechos recopilados por la historia emana un íntimo vacío de motivaciones, sentimientos y deseos comunes que solo el arte puede transmitir, especialmente la literatura, por ser el lenguaje su herramienta de creación, herramienta que es a un tiempo producto de la colectividad y del genio individual del poeta, «feliz armonía de lo individual con lo general». ${ }^{46}$ De este modo, Giner desplazaba a la historia de su posición privilegiada en la captación del transcurrir de los pueblos y civilizaciones identificando un poso significativo de humanidad que primordialmente nos es revelado por la literatura:

De esta suerte no es otra cosa la literatura que el primero y más firme camino para entender la historia realizada; mentor universal, nos reproduce lo pasado, nos explica lo presente y nos ilustra y alecciona para las oscuras elaboraciones de lo porvenir. ${ }^{47}$

Así, en la literatura de todos los tiempos viene a palpitar la razón de ser de las distintas civilizaciones. Razón de ser que es atisbada en la coyuntura entre la vida pensada o contada (Historia) y la vida vivida (Vida), asumiendo la arbitrariedad de la correspondencia entre ambas que solo viene a deshacerse temporalmente cuando la literatura la ilumina con el ideal de lo humano histórico y permanente. Según lo dicho, el carácter de una nación para Giner de los Ríos encuentra su más adecuado cauce de

\footnotetext{
45 El determinismo del carácter de una nación es tomado de la filosofía de la historia de Herder, sobre todo por su concepción orgánica de la sociedad plasmada en la metáfora 'botánica' del crecimiento de las plantas que tanto habría de influir en todo el pensamiento decimonónico con especial énfasis en Julián Sanz del Río y sus seguidores, y puesto en relación directa con el arte y la literatura por Augusto Guillermo Schlegel, poderosamente influyente con sus Lecciones sobre el arte dramático y literatura en la constitución del movimiento romántico. Desde esas Lecciones se postula el radical vínculo del arte con el espíritu de la época.
}

46 López Morillas, Krausismo: estética y literatura, Barcelona, Labor, 1973, p. 113.

47 López Morillas, Krausismo: estética y literatura, Barcelona, Labor 1973, p. 114. 
expresión en la literatura por cuanto lo humano eterno junto a lo humano específico, caras de una misma moneda, aparecen en su forma ideal. Y es este ideal de ser de la nación el elemento ausente que los escritores españoles de la época, influenciados por el pensamiento de Giner, tratan de sacar a la luz. Por otra parte, este concepto íntimo de la historia que maneja Giner y que andado el tiempo verá su correspondencia con el concepto unamuniano de intrahistoria, no hay que olvidar que tiene su origen en la filosofía de la historia de Krause y que este a su vez lo integra como una de las claves interpretativas de su tiempo:

Krause establece una distinción entre historia externa e historia interna, considerando que es esta la verdadera. Esta interpretación supone un ideal de futura perfección humana en el que las crisis son efímeros paréntesis. No está de más señalar, como lo ha hecho López Morillas, que esa actitud que cunde por Europa en el siglo pasado, tiene sus antecedentes en el movimiento romántico, cuando se generaliza la distinción entre historia interna y externa. ${ }^{48}$

\section{LA ESTÉTICA DE PÉREZ DE AYALA Y LA CONCIENCIA DE LA NACIÓN}

En la problemática que abren el regeneracionismo y el krausismo se insertan las ideas estéticas de Ramón Pérez de Ayala. La estética del escritor asturiano surge como solución al «problema de España». La cuestión es dotar a los españoles de sensibilidad mediante el arte. ${ }^{49}$

Su estética se encuentra de un modo explícito en la novela Troteras y danzaderas (1913). Para Ayala el sentido estético es la facultad que aúna todos los sentidos corporales para la apreciación ecuánime de la realidad:

Somos una raza con los sentidos romos, a través de los cuales la realidad apenas si se filtra a intervalos y deformada, por donde la inteligencia está de continuo en aquel punto de esfuerzo nebuloso y desazón gustosa, como decían los místicos, como si Dios en persona estuviera para revelársele en su interior morada. ${ }^{50}$

Educar a la sociedad a hacer buen uso de sus sentidos e imaginación se interpreta como un modo de sustraerse al arrastre de la acción monolítica de la razón tanto como al sensualismo desquiciado. Ambas correcciones sobre el hombre, la de aprender a sentir para poder pensar (en el sentido de comprender la realidad íntegramente), es un característico programa educativo de signo krausista, ${ }^{51}$ en tanto que la estética se presenta estrechamente unida y ensamblada a un fin moral:

\footnotetext{
48 Jongh - Rossel, El krausismo y la generación del 98, Valencia, Albatros - Hispanófila, 1985, p. 163.

49 «En resumen, que para ti el problema está en dotar de una sensibilidad a la casta española, y esto sólo lo puede hacer el arte», en: Pérez de Ayala, Obras completas, Madrid, Aguilar, 1963, p. 711.

50 Pérez de Ayala, Obras completas, Vol. I, Madrid, Aguilar, 1963, p. 599.

51 Esta noción pedagógica a la que me refiero es uno de los principios educativos de la ILE, la denominada educación integral (mente, cuerpo y sentimientos): «[...] se aspira a una formación completa del
} 
Sin sentidos y sin imaginación, la simpatía falta; y sin pasar por la simpatía no se llega al amor; sin amor no puede haber comprensión moral, y sin comprensión moral no hay tolerancia. En España todos somos absolutistas. ${ }^{52}$

Por tanto, Pérez de Ayala, destaca la comprensión como el objetivo último de su empresa estética. Esta comprensión íntima de la razón de ser de todo lo real es la clave del llamado perspectivismo, que desarrollaría por aquellos años Ortega y Gasset. Regenerar la sociedad española es, desde estos presupuestos, acercarla a la comprensión de sí misma, y en última instancia, de su lugar en el mundo. Dicha estética se presenta como solución al «problema de España», y, teniendo en cuenta que este es un problema que se enraizaba en el carácter de la nación o «alma española», ${ }^{53}$ parece seguirse lógicamente que el autor, y así el protagonista de la obra, ha tomado conciencia de dicho carácter, que, además, como español, lo constituye a él individualmente. Don Sabas reflexiona sobre el problema de España y su posible solución: «el ideal es el mejor estimulante de la alta cultura ${ }^{54} \mathrm{y}$ «el ideal no se construye sino con la imaginación» ${ }^{55}$; pero, y aquí está el enlace con el carácter de la nación: «El pueblo español no tiene imaginación». ${ }^{56}$ Esta toma de conciencia que hace Alberto Díaz de Guzmán es crucial, puesto que le permite ascender un grado más en la escala de reintegración con la idea de la humanidad. El recorrido hacia la armonía universal que efectuará el joven artista, ${ }^{57}$

alumno tanto en el aspecto intelectual o físico como afectivo, por lo que se rechaza cualquier asomo de parcelación en la obra educadora con el cultivo exclusivo o prioritario de alguna de las funciones aludidas», en: A. Molero Pintado, La institución libre de enseñanza. Un proyecto de reforma pedagógica, Madrid, Biblioteca Nueva, 2000, p. 81.

52 Pérez de Ayala, Obras completas, Madrid, Aguilar, 1963, p. 599.

53 R. Cardwell, refiriéndose a la génesis de las raíces intelectuales de los escritores de fin de siglo, destaca el concepto de «carácter nacional» como compartido por diferentes corrientes de pensamiento en el siglo XIX, entre ellas el krausismo: «It seems also that the concept of a national alma, imported from German Romanticism and adapted by Böhl von Faber, employed by the Fernandine critics to define Romanticism and to support Throne and Altar in a time of crisis, also played its part. Strengthened in part by Krausism and given a scientific base by the advent of Positivist sociology, anthropology and the rise of folklore studies, this dominant idea underwent a series of transformations and was used by conservatives and liberals alike», en R. Cardwell, «Antonio Machado and the search for the soul of Spain: a genealogy», en: Anales de la literatura española contemporánea, Vol. 23, No 1-2, 1998, p. 75.

54 Pérez de Ayala, Obras completas, Madrid, Aguilar, 1963, p. 704.

55 Pérez de Ayala, Obras completas, Madrid, Aguilar, 1963, p. 704.

56 Pérez de Ayala, Obras completas, Madrid, Aguilar, 1963, p. 704. Adviértase aquí que las palabras de Sabas, si bien no coinciden en los términos con las de Alberto, el portavoz habitual del autor, significan lo mismo: solo que don Sabas comienza la cadena de deducciones sobre el carácter español desde la consecuencia de la primera premisa de Alberto: «Un pueblo que no tiene sentidos no tiene imaginación», en Pérez de Ayala, Obras completas, Madrid, Aguilar, p. 599.

57 En un interesante artículo del Donald L. Fabian, siguiendo el «Prólogo» de Pérez de Ayala a Troteras y danzaderas (1942), se interpreta este proceso del protagonista de la tetralogía como un proceso de maduración del artista siguiendo tres fases, desde el egoísmo «expansivo e ingenuo» hasta la asimilación de las formas del arte como «normas perdurables y eternas» y pasando por un estado intermedio de «confusión, desilusión y aridez». Ni que decir tiene que la estructura marcada refleja nítidamente el perfeccionamiento de la humanidad según el krausismo, sólo que en este caso el crítico se queda en una 
como compendio de la humanidad entera, en la última parte de La pata de la raposa, «La tarde», pasa a través de la continua y plural oposición de ideas y perspectivas. Los mismos títulos que encabezan las diferentes partes de que consta el libro de Troteras y danzaderas son ejemplos elocuentes de ello. Así, «Sesostris y Platón», " y Desdémona», ${ }^{59}$ «Troteras y danzaderas», ${ }^{60}$ «Hermes Trismegisto y Santa Teresa», ${ }^{61}$ «Ormuz y Ahriman». ${ }^{62}$ Es importante observar que entre todos estos opuestos se puede entresacar o abstraer un carácter común - como he procurado hacer patente en las notas explicativas que he dedicado a estos nombres -: representan, respectivamente, la oposición entre lo exterior y lo interior. O lo que es lo mismo: naturaleza y espíritu; entendiendo que el elemento que diferencia a ambos es la conciencia o pensamiento con que se identifica el espíritu. Si se entiende la trayectoria de Alberto Díaz de Guzmán como un trasunto del progreso de la humanidad que defendía el krausismo, tal y como vengo exponiendo, este sistema plural de oposiciones que vertebra la obra - y tras el que, cronológicamente, se fragua el estado armónico del protagonista descrito en «La tarde» -, toma un sentido pleno. Todos los títulos de que consta Troteras y danzaderas

mirada parcial que solo concierne al desenvolvimiento del Arte, pero que de alguna manera conecta con lo expuesto en estas líneas de mi estudio, teniendo en cuenta que tanto para el krausismo como para Pérez de Ayala Arte y vida son una misma cosa; y todo a pesar de que en este artículo que comento el autor niega expresamente el que la tetralogía se pueda percibir como un proceso en el que individuo y sociedad (española y universal) vayan parejos (referidos recíprocamente) y al unísono: «El proceso integrante y liberador que Alberto experimenta es, en realidad, como lo describe Ayala en el «Prólogo» a Troteras y danzaderas, un madurar que puede interpretarse como las experiencias que cada artista tiene que vivir durante su desarrollo. (La aplicación generalizada a la sociedad española y, en sentido más amplio, a la europea, de esta teoría de la maduración la esboza Pérez de Ayala en el citado «Prólogo»; en las novelas propiamente dichas, sin embargo, no desarrolla el tema a este nivel. Aquí se considera simplemente el tema en lo que a la expresión recibida en las novelas se refiere)». Donald L. Fabian, «El progreso del artista, tema principal de las primeras novelas de Pérez de Ayala», en La novela lírica, II. Pérez de Ayala y Jarnés, Darío Villanueva (ed.) Madrid: Taurus 1983, p. 108.

58 Sesostris fue un legendario rey de Egipto de la $12^{\mathrm{a}}$ Dinastía que llegó a conquistar todo el mundo conocido. Símbolo del poder terrenal. Platón, filósofo griego, nacido en el 427 a. C en Atenas, fiel a las enseñanzas de su maestro, Sócrates, es el paradigma del idealismo filosófico clásico postulando que el mundo real tiene un correlato modélico en el mundo de las ideas. Ambos personajes históricos y legendarios pueden considerarse conquistadores: el primero del orbe terreno; el segundo, del orbe del pensamiento y la cultura.

59 Verónica, es la prostituta de la que Alberto Díaz de Guzmán aprende la teoría estética del con fundirse y trans - fundirse con la realidad toda, ella realiza el papel de espectador de la teoría clásica. Desdémona es el personaje protagonista de la conocida obra de Shakespeare, el Otelo, cuya lectura y adaptación se da en ese capítulo de Troteras y danzaderas. Ambos experimentan fuertes emociones en el transcurso de la obra, Verónica como espectador, Desdémona como personaje actante.

60 Tomado del Arcipreste de Hita, tanto troteras como danzaderas son modos de escenificación: troteras podría indicar marcha o caminata festiva (para las que el Arcipreste de Hita habría compuesto muchas canciones para ser cantadas por el camino); y danzaderas serían bailes populares, la danza se asimila en la obra con el misticismo.

${ }^{61}$ Hermes Trismegisto o Trismegistus, sabio y astrólogo. Santa Teresa de Ávila, fundadora de la Orden del Carmelo, religiosa y mística. Ambos escrutan la providencia divina, uno en los astros, la otra en sí misma.

62 Ormuz (Ahura Mazda) y Ahriman (Angra Mainyu) son los principios opuestos que conforman la cosmogonía del libro sagrado persa, el Avesta, atribuido a Zoroastro. 
hacen referencia a conceptos liminares de la doctrina krausista como son la oposición existente entre naturaleza y espíritu, y la armonía que dicha oposición encuentra en el seno de la humanidad a través de su transcurso histórico.

El hombre, siendo el compuesto armónico más íntimo de la Naturaleza y el Espíritu, debe realizar históricamente esta armonía y la de sí mismo con la Humanidad, en forma de voluntad racional y por el puro motivo de esta su naturaleza en Dios. ${ }^{63}$

Esta armonización, o unidad en la pluralidad, se puede observar igualmente en los epígrafes a los que me vengo refiriendo: así, tanto Sesostris como Platón llevaron a cabo actividades omniabarcantes, aunque en diferentes direcciones; Hermes Trismegisto y Santa Teresa escrutan la Providencia divina, uno desde la astrología, la otra desde la unión mística con Dios; Verónica y Desdémona comparten emociones, una como espectadora, la otra como sujeto de la acción (actriz); Ormuz y Ahriman, principios creadores del universo en la etiología persa, uno simboliza la materia eterna y el otro la forma, o naturaleza y espíritu.

Por último, habría que sacar algunas conclusiones someras sobre la parte titulada «Troteras y danzaderas», que es la que da nombre al libro en su totalidad. En el interesante diálogo que sostienen Alberto Díaz de Guzmán (Pérez de Ayala) y Alberto Monte-Valdés (Valle - Inclán) se intentan definir las actividades más características de España en relación con su expresión en el léxico del idioma. Estas actividades son tres: la danza, el misticismo y la embriaguez. Ambos llegan al acuerdo de que las dos primeras están intrínsecamente relacionadas: «La danza es un arte eminentemente místico y español». ${ }^{64} \mathrm{Y}$ esto hay que relacionarlo con el título del libro, que refleja el carácter o el producto más genuino del pueblo español: «¿Qué es lo que ha producido España?. Sepámoslo. - Troteras y danzaderas, amigo mío; troteras y danzaderas». ${ }^{65}$

Teniendo en cuenta lo dicho arriba, los tres elementos más característicos de España habrían de aparecer en el título, como de hecho sucede: «danzaderas», que integra la danza y la mística; «troteras», que encerraría el concepto de embriaguez corporal, símbolo de aquellas marchas festivas o pasacalles para los que Juan Ruiz habría hecho muchas cantigas. Pero esa embriaguez corporal tiene su correlato en el misticismo, el cual se asimila con una cierta embriaguez espiritual: «Hemos inventado mayor número aún de vocablos para designar otro acto que, si no es precisamente místico, pudiera tener alguna concomitancia con ciertas formas de misticismo». ${ }^{66}$

\footnotetext{
63 He aquí, en ese párrafo, el criterio regulador del Ideal de la humanidad para la vida. K. Ch. F. Krause / J. Sanz del Río, Ideal de la humanidad para la vida, Barcelona, Folio, 2002, p. 37.

64 Pérez de Ayala, Obras completas, Madrid, Aguilar, 1963, p. 648.

65 Pérez de Ayala, Obras completas, Madrid, Aguilar, 1963, p. 816.

66 Pérez de Ayala, Obras completas, Madrid, Aguilar, 1963, p. 648.
} 
De ahí se sigue que el elemento persistente en el carácter español es el de la embriaguez, tanto corporal (el alcohol y las fiestas) como espiritual (por el misticismo y la danza); y esto entra en concierto con la opinión que de la raza española tiene Pérez de Ayala, expresada por medio de Alberto, en la misma novela, y que transcribí más arriba: «somos una raza con los sentidos romos».

Dicho esto, se puede entender con algo más de profundidad la validez que el proceso de perfeccionamiento de la humanidad (esto es, la integración sucesiva del individuo mediante la comprensión o toma de conciencia de su pertenencia esencial a los diferentes grupos humanos superiores: región, nación y humanidad), tiene en la descodificación de la tetralogía de Pérez de Ayala, especialmente en su Troteras y danzaderas. Pues, habiéndose hecho conciencia en Alberto Díaz de Guzmán el carácter español, se predispone a su inserción en el componente infinito y universal de la realidad humana, o si se quiere, una vez que ha encontrado su puesto entre los de su nación, según el carácter peculiar de esta, llega el momento de la armonización de su ser con el de la humanidad. ${ }^{67}$ Estaríamos ya en «La tarde», última parte de La pata de la raposa. Armonía buscada, como se ha dejado ver más arriba, desde el mismo título de Troteras y danzaderas, y las secciones en que este está dividido, expresada como la oposición entre naturaleza y espíritu.

\section{A MODO DE CONCLUSIÓN: HACIA EL IDEAL DE LA HUMANIDAD}

En el transcurso de este estudio, partiendo de las tesis de Prieto Jambrina, he rastreado el influjo de la doctrina krausista y de la ley histórica del krausismo, en cuanto al progreso de la humanidad, en la tetralogía ayalina - labor que no se realiza en El humanismo armónico de Ramón Pérez de Ayala, por considerar su autor a esta tetralogía como una parte supeditada a un plan novelístico más amplio, siguiendo el «Prólogo» de 1942 -, lo cual impide un análisis de la primera como obra unitaria y con pleno sentido en sí misma; así, también, he analizado e interpretado a la luz del krausismo la estructura y el título de una de las obras más emblemáticas del escritor asturiano: Troteras y danzaderas.

La obra temprana de Pérez de Ayala se ha mantenido fiel a un objetivo principal que ha sido el de educar a sus congéneres en la comprensión de la realidad y de su deber como hombres de progresar hacia la realización del fin común de la humanidad.

67 Pérez de Ayala, en el prólogo a la edición argentina de su Troteras y danzaderas, con una distancia de unos 30 años, aún mantiene su convicción de estirpe krausista acerca de la necesidad de expresar lo esencial humano desde la realización plena de los caracteres individuales (regionales) y nacionales: «Lo universal no puede manifestarse sino a través y por medio de lo nacional; y de aquí que lo nacional es lo que universaliza al hombre individual». Pérez de Ayala, Troteras y danzaderas, Buenos Aires, Losada, 1942 , p. 8. 
Para ello ha querido alentar a los individuos de su propia nación a implementar aquellas facetas en que se encontraban más disminuidos, la vista siempre puesta en un ideal de ser humano que solo por la integración perfecta con sus congéneres, primero, y con un plan cósmico, después, puede hallar la plena liberación y realización de sus potencias. De este modo, el destino de la humanidad, en su diseño krausista de unidad indiferenciada, pluralidad y armonía universal, ha sido efectuado en la biografía de Alberto Díaz de Guzmán. En ella el protagonista, trasunto de la humanidad, sale de su ingenua instrucción en $A M D G$, como unidad simple, pura espiritualidad ingenua del niño Bertuco, para comenzar la pluralización de perspectivas en Tinieblas en las cumbres, especialmente en el «coloquio superfluo», en que Yiddy y Alberto representan la dialéctica entre naturaleza y espíritu, por el materialismo del primero y el espiritualismo del segundo; esta pluralidad de perspectivas pasa por las dos primeras partes de La pata de la raposa, donde entran en colisión las actitudes contrarias de la abulia y del vitalismo desaforado, Schopenhauer y Nietzsche, respectivamente; y ese continuo oponerse de perspectivas toma su más rotunda expresión en Troteras y danzaderas. Por último, en «La tarde», última parte de La pata de la raposa, se alcanza la expresión armónica de vida y arte, integrándose como individuo en la universalidad humana mediante la objetivación de su mundo interior, espectador de sí propio como microcosmos. Aunque en este capítulo se dé la noticia de la muerte de Fina, episodio trágico, en un principio, para el protagonista, este desenlace fatal es el que lo libera irónicamente para su realización última a través del compromiso con su país, pues como el mismo protagonista dice, en un mensaje de esperanza y de vida, fruto de su experiencia interior y su autodominio recién conquistado: «Aún hay sol en las bardas». ${ }^{68}$ Ha llegado a un estado de equilibrio desde el que todos los acontecimientos encuentran su explicación y acomodo, y desde el que Alberto toma conciencia de su vocación de escritor comprometido. Desde otros presupuestos, así también lo entiende M. D Albiac:

En la segunda parte Alberto se despide de la virginal Fina para forjarse un porvenir en la capital como escritor y volver a la aldea a fundar juntos una familia; pero en la tercera parte - han pasado tres años - Alberto sigue buscando su lugar personal y ese equilibrio que nace de la confluencia de reflexión y autodominio, con pasión y sentimiento. Díaz de Guzmán, momentáneamente tentado por el horacianismo de un poema de Whittier, regresa a la aldea pero Fina ha muerto. Este final, posterior a los hechos de Troteras y danzaderas, cierra la saga, y es, desde supuestos novelescos, feliz, pues libra al protagonista de su mala conciencia con Fina, de la tentación de huida, y le facilita ser el creador comprometido y liberal que apunta en Troteras. ${ }^{69}$

\footnotetext{
68 Pérez de Ayala, Obras completas, Madrid, Aguilar, 1963, p. 468.

69 M. D. Albiac Blanco, «Ramón Pérez de Ayala», en Boletín Informativo de la Fundación Juan March, Ensayos, nº 12, marzo (2003), p. 10.
} 
En este proceso, siguiendo el pensamiento krausista, la integración del individuo como parte en el todo que es la humanidad exige la integración de este en los componentes superiores, los grupos humanos, llamados «hombres mayores» por Julián Sanz del Río, que son la región (AMDG, Tinieblas, La paz del sendero, La pata de la raposa) y la nación (Troteras y danzaderas), como conciencia del carácter propio de estos. Según este esquema y todo lo referido más arriba, la tetralogía es una recreación, ejemplo y exposición propedéutica de la ley histórica que se desarrolla en Ideal de la humanidad para la vida:

$\underline{A M D G}$

- Unidad indiferenciada

- Localidad

- Individuo (yo)

- Espiritualidad ingenua

\section{Tinieblas / La pata / Troteras}

- Pluralidad /oposiciones

- Región y nación

- Espíritu / materia

- Abulia / vitalismo
La pata («La tarde»)

- Armonía

- Humanidad

- Universo

- Realización

Como se ha pretendido mostrar, la idealidad que refleja la literatura de Pérez de Ayala, en su materia y en su forma, y el empeño en la educación estética colaboran en un más amplio proyecto krausista de regenerar la simiente de la nación española, para recuperar, mediante una cierta concepción deudora del historicismo romántico, su carácter e idiosincrasia eterna; y, así, desde ella, colaborar en el progreso del consorcio de naciones que forman la humanidad. Por ello, y siguiendo las enseñanzas de Francisco Giner sobre la idoneidad de la literatura como expresión del carácter de la nación, Pérez de Ayala trabajará para construir y mostrar con su obra el camino del ideal y la consecución del fin propio de su patria. O lo que es lo mismo, en palabras de Donald Fabian: «Thus from end to end of his career Ayala remained faithful to an art of the Ideal». ${ }^{70}$

\section{Bibliografía}

AMORÓS, A., Vida y literatura en «Troteras y danzaderas», Madrid, Castalia, 1973. ALBIAC BLANCO, M. D., «Ramón Pérez de Ayala», en Boletín Informativo de la Fundación Juan March, Ensayos, nº 12, marzo (2003), pp. 3 - 12. BOBES NAVES, M. C., «Renovación del relato en las primeras novelas de D. Ramón

70 Donald L. Fabian, «Modernismo, idealism and the intellectual crisis in Spain, 1895 - 1910», en: Renaissance and Modern Studies, Volume XXV, Nottingham, University of Nottingham, 1981, p. 36. 
Pérez de Ayala», en Pérez de Ayala visto en su centenario. 1880 - 1980. Oviedo, IDEA, 1980, pp. 71 - 97.

CAPELLÁN DE MIGUEL, G., La España armónica, Madrid, Biblioteca Nueva, 2006.

CARDWELL, R. A., "Antonio Machado and the search for the soul ofSpain: a genealogy», en Anales de la literatura española contemporánea, Vol. 23, № 1- 2, (1998), Society of Spanish and Spanish-American Studies, University of Colorado-Boulder , pp. $51-80$.

FABIAN, D., «Modernismo, idealism and the intellectual crisis in Spain, 1895 -1910» en Renaissance and Modern Studies, Volume XXV, (1981), Nottingham, University of Nottingham, pp. 25 - 39.

«El progreso del artista, tema principal de las primeras novelas de Pérez de Ayala», en La novela lírica, II. Pérez de Ayala y Jarnés, Darío Villanueva (ed.) Madrid, Taurus, 1983, pp. 108 - 116.

JONGH ROSSEL, Elena M., El krausismo y la generación del 1898, Valencia, Hispanófila, 1985.

KRAUSE, K. Ch. F., Compendio de estética, Traducido por Giner de los Ríos, Madrid, V. Suárez, 1883.

KRAUSE, K. Ch. F. / J. SANZ DEL RÍO, Ideal de la Humanidad para la vida, Barcelona, Folio, 2002.

LÓPEZ MORILLAS, J., Krausismo: estética y literatura, Barcelona, Labor, 1973.

MOLERO PINTADO, A., La institución libre de enseñanza. Un proyecto de reforma pedagógica, Madrid, Biblioteca Nueva, 2000.

PRADO, M. A., Tigre Juan. El curandero de su honra, Madrid, Cátedra, 2001.

PÉREZ DE AYALA, R., Obras completas de Ramón Pérez de Ayala, Vol. I, García Mercadal (ed.), Madrid, Aguilar, 1963.

, Tributo a Inglaterra, Madrid, Aguilar, 1963.

, AMDG, Madrid, Cátedra, 1995.

, Troteras y danzaderas, Losada, Buenos Aires, 1942.

PRIETO JAMBRINA, J. R., El humanismo armónico de Ramón Pérez de Ayala, Alicante, Universidad de Alicante, 1998. 